\section{THE ILLUMINATED FOUNTAINS AT THE} HEALTHERIES

NOW that the most successful of International Exhibitions has been closed, we are able to give the final result of the accumulated experience that has been obtained in connection with the working of the illuminated fountains, which excited unqualified admiration. Even on the last night we believe new experiments were tricd, and next season these fountains are likely to be finer than ever.

"I wonder how it is done?" This was one of the remarks most frequently heard in the dense crowd which nightly surrounded the large fountain at the Health Exhibition, watching the many party-coloured jets of water as they rose and fell with an ever-varying combination of brilliant hues. It is believed that an account of the means employed to produce these gorgeous and novel effects, and of the way in which the water and lights were managed, cannot fail to interest our readers.

The water-supply is obtained from the West Middlesex Water Company by means of a nine-inch main, which is connected to one of their mains in Kensington Gore. As the water is paid for according to quantity used, it has to be measured, and in order to effect this with as little loss of pressure as possible, the water is passed through three eight-inch Tyler meters, which are to be seen at the north-west corner of the grounds in the vicinity of the fountains. These meters are connected at each end by a four-way junction piece to the nine-inch main, and they were afterwards supplemented by a twelveinch one on a separate branch. From the four meters the main passes under the water into the central chamber in the basin, and it there branches into three pipes, two of nine inches diameter, and one of six inches. The two nine-inch pipes go round the two sides of the chamber, which is twenty feet square, and are connected together at the opposite side, thus forming a loop round the chamber. Off this main are taken the supplies to the four rings of jets in the basin, and also for the jets on the top of the chamber, each ring having two supplies at opposite sides in order to equalise the pressure. The third branch, which is in direct continuation of the main from the meters, is gradually reduced to three inches, and supplies the centre jet only.

All the supplies are furnished with screw valves worked by hand wheels. The jets on the top of the chamber consist of the centre jet and four other jets placed at the four corners; each of these jets is surrounded by a ring of twelve small jets, and there are also four dome and convolvulus jets placed between the corner jets. The supply to the four corner-jets is controlled by a plugvalve, so that they can be rapidly turned on and off. It is by this means that the jumping of the centre-jet is produced, the momentum of the water flowing through these jets being sufficient, on the sudden closing of the valve, to jerk the centre jet thirty feet higher than the point which it reaches from the pressure of the mains alone.

In order to light up the various jets on the top of the chamber, five circular sheets of glass two feet in diameter are let into the flat roof of the chamber, one under each jet. The pipes leading to these jets go through the roof close to the edge of the glass, and are then bent over it and upwards again, so as to bring the jet itself exactly over the centre, and it is under these panes that the lighting apparatus is placed. This consists of a simple bracket lamp with rack and pinion worked by hand for feeding the carbons, and a third-order holophote lens twenty-two inches in diameter. The carbons are placed at an angle of about $20^{\circ}$ with the horizon, and the bottom carbon is the positive one, in order to have the crater turned upwards. The axis of the top carbon is also slightly above that of the lower one, although parallel to it. The carbons are eighteen millimetres in diameter, and the current is about sixty amperes. The five lamps are connected in parallel. Each lamp is inclosed in a case to protect the men from the light. Above each holophote is placed a frame with five grooves, in which run five frames containing the different coloured glasses by which the various colours are produced.

When first erected the jets were provided with glass bottoms, and a small lens was placed above the holophote so as to concentrate the centre portion of the ray on the interior of the rising column of water. It was however found that this arrangement considerably reduced the height of the jet, on account of the eddies produced in the chamber at the bottom of the jet, and also diminished the amount of light thrown on the spray, and it was therefore abandoned.

The principle of interior lighting of a stream of water was applied to three jets from the top of the Corinthian columns erected on each side of the statue of the late Prince Consort, and for this purpose two two-inch pipes were taken up each column, and connected with a cistern from which issue three jets, each illuminated from behind

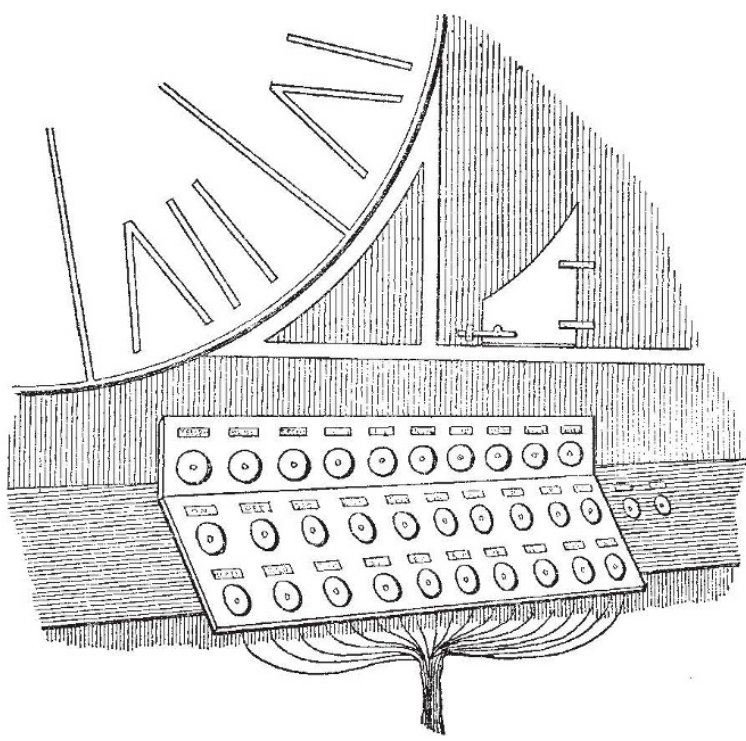

by an electric lamp with twelve-millimetre carbons and twenty-ampere current. These lamps are in parallel arc on the same circuit as the large lamps in the centre chamber, suitable resistances being inserted. It was found that the two supplies provided did not allow of a column of water of sufficient diameter being thrown from each jet to prevent its being broken up by the wind, and as it was impossible to increase the supply while the Exhibition was open, these effects were rarely used. The current for these eleven lamps, amounting to 420 amperes, is generated by a compound shunt-wound Simens $B_{2}$ machine flaced in the electric light shed. The armature of this machine is built up of copper strips with spaces between, and is thus especially adapted for the work it has to do, which at times is very severe, as, the lamps being hand-fed, the arc is not struck as rapidly as in an automatic lamp, and the machine is therefore shortcircuited for an appreciable space of time on starting or relighting any lamp. The electromotive force at the machine is eighty-four volts. From the machine the current is conveyed to the small hut near the meters by two well-insulated cables of nineteen strands of No. 12 copper wire, and from the hut it is distributed to the island lamps by an insulated cable of nineteen No. 10 wires 
inclosed in a lead pipe, and to the columns by two cables of seven strands of No. I2. A separate return cable runs from each lamp to the hut, where it is connected to the necessary resistances, made of strip iron, and from there back to the dynamo through two cables of nineteen No. r2's. There is altogether very nearly a ton of copper in the various leads and branches. Besides these leads the centre chamber is connected to the circuit of the Sun light machine, so that, should any accident occur to the main circuit or michine, Sun lights could be substituted for the hand lamps.

As the falling spray cuts off the light from below when the jets are at their highest, a light is placed in the top of the clock tower to illuminate the top of the jets. This light is a focus-keeping Siemens automatic lamp, and takes a current of fifty amperes, supplied by a small Crompton-Burgin machine. The lamp is inclosed in a cast-iron casing swung on trumnions, and in front of it is a fifth-order holophotal lens by Messrs. Siemens.

The various coloured glasses are fixed in frames or sashes arranged with counterweights, in the same way as an ordinary window. Some of the best effects of colour are also obtained by sheets of gelatine, of which a large number are fastened end to end, and fixed to two rollers, so that they can be wound from the one to the other, and thus passed through the beam of light.

As the men in the centre chamber cannot see the effects they produce, it is necessary to direct them from the outside, and this is effected by an elaborate system of electric bells and disks, which are worked from the clock chamber below the last-described holophote. In this chamber sits Sir Francis Bolton, with a treble row of "pushes" in front of him, all labelled, by touching any of which a corresponding disk or bell is worked in the island. There are four bells - a call bell, an "on" bell, an "off" bell, and a lamp bell-and two indicator boards with eight disks each, and one with four. One board is for the water valves, which are each painted a different colour, with the corresponding colour on the disk, and the second board for the coloured glasses over the holophotes. The disks on the small board refer to the corner lamps, and by their means Sir Francis can direct any colour to be placed over any one of the lamps by touching the push corresponding to the lamp and the push marked with the colour which he wishes to show. The working of the holophote at the top of the clock is directed in the same way.

\section{EXPERIMENTS WITH COAL-DUST AT NEUNKIRCHEN IN GERMANY}

$\mathrm{D}$

URING the course of the last summer the Royal Prussian Fire-damp Commission has carried out a series of experiments in the Saarbricken mining district with the view of ascertaining the influence which coaldust has, alone and in conjunction with firc-damp, in propagating explosions in mines. The apparatus and the mode of experiment were suggested by retired Bergwerksdirector and Bergassessor Hilt, of Aix-la-Chapelle, who is a member of the Commission, and the results hitherto obtained have been of the most interesting kind.

The experiments are conducted at the Royal Coal Mine, König, near Ncunkirchen, where there is a blower of fire-damp at a depth of 131 yards below the surface. The quantity of fire-damp given off by this blower amounts to about 0.9 cubic foot per minute, consisting of $\$ 6$ per cent. of light carburetted hydrogen mixed with air, \&c. It has been in existence for the last two years. The firedamp is brought a distance of 1200 yards in pipes, and collected in a small gasometer whose capacity is 176 cubic feet.

Dr. Ad. Gurlt of Bonn lately called my attention to the fact that over two hundred experiments made with this apparatus on a large scale had proved the correctness of my theory of great collicry explosions (Proc. Roy. Soc., vol. xxiv. p. 354, \&c.), and at the same time suggested that a visit to Neunkirchen would be of interest.

Accordingly I proceeded to the scene of the experiments on October 25, accompanied by Mr. Wm. Thomas Lewis, one of the members of the Royal Commission on Accidents in Mines, and we were met there by Dr. Gurlt, who had travelled from Bonn for the purpose, and by Herren Prietze, Nasse, Margraf, and Kreuser, directors and assistant-directors of König Grube and other Royal mines of the neighbourhood. Herr Margraf, under whose superintendence all the experiments are and have been made, has most kindly furnished me with a detailed description of the apparatus and of the experiments witnessed by Mr. Lewis and myself, and I am glad to avail myself of, and shall endeavour to reproduce, his account as nearly as may be, allowance being made for the difficulties of exact translation.

The experiments are made in a horizontal wooden gallery 167 feet long, closed at one end, and having a horizontal branch gallery 33 feet long standing out at right angles to it at a distance of 93 feet from its closed end. Both the main gallery and the branch consist of elliptical rings of double 'T-iron lined internally with planks I 6 inch thick, which abut closely together and are grooved and feather-jointed lengthwise. The greater axis of the ellipse stands vertically, and is about 5 feet 7 inches long; the lesser axis is 3 feet II inches long. The main and branch galleries are both embedded in the pit-heap to such a depth that the rubbish is level with their top on one side and reaches to threequarters of their height on the other side. Along the exposed part of the latter side there is a row of windows, thirty-two, in the main gallery, and three in the branch gallery, situated somewhat more than a yard apart. They are formed of sheets of glass about $\frac{2}{3}$ inch thick set in cast-iron frames. There are also a number of openings in the top of the main gallery, one of which, near the closed end, is an ordinary man-hole, which can be closed by a man-hole door like that of a boiler, and serves as a means of ingress and egress. The others are circular, about 9 inches in diameter, and are lightly closed with wooden plugs attached to chains, which act as safety valves. All these openings assist in the removal of afterdamp after an explosion.

The closed end of the main gallery is sunk about 3 feet 9 inches into a block of masonry whose dimensions are 12 feet 4 inches long, 9 feet 9 inches wide, and $I_{3}$ feet high. Seven cast-iron camnon, with a bore similar to that of a shot-hole in hard ground, are built into the block in the position shown in the figure oppositc, so that their mouths are flush with the face.

There are two holes near the top, two near the bottom, and three in the middle, grouped symmetrically in relation to the two axes of the ellipse. The middle hole is 37 inches deep by 1.57 inch in diameter; the others are $31 \frac{1}{2}$ inches deep by 1.37 inch in diameter. The axes of the two upper and of the two lower holes are placed in such a position that they form the angles of a four-sided regular prism whose apex is situated in the axis of the main gallery at a distance of $16^{\circ} 4$ feet from the face. The axes of the thrce middle holes constitute a bundle of rays which meet at the same point as the last. Wooden hoops projecting inwards from the sides are placed at various distances apart in the main gallery within the first $65 \frac{1}{2}$ feet from the face. By fastening cloth diaphragms to these hoops, compartments of various capacity can be formed, that of the first next the face being 705 cubic feet.

The shots are fired electrically with Abegg's fuses by means of an exploder made by Mahler and Eschenbacher of Vienna. The charge, which consists of 230 grammes, or about half a pound, of powder, occupies a length of 8.64 inches in the central hole, leaving room for rather 